\title{
Pension Freezes and Household Saving Over the Life Cycle
}

\author{
David A. Love* \\ Paul A. Smith ${ }^{\dagger}$
}

October 27, 2008

\begin{abstract}
Defined benefit (DB) pension freezes in large healthy firms such as Verizon and IBM, as well as terminations of plans in the struggling steel and airline industries, highlight the fact that these traditional pensions cannot be viewed as risk-free promises from the employee's perspective. Indeed, the current turmoil in financial markets and difficult economic outlook for many firms suggest that many more pension plans could be frozen soon. In this preliminary paper we develop an empirical dynamic programming framework to investigate household saving decisions in a model economy with freezeprone DB pensions. The model incorporates important sources of uncertainty facing households, including asset returns, employment, income, and mortality, as well as pension freezes. Applying a compensating variation measure of welfare, we find that pension freezes reduce welfare by a maximum of about $\$ 6,000$ for individuals with a high school degree and about $\$ 2,000$ for individuals with a college degree. We close by highlighting a few important issues that are missing from our preliminary analysis, including a labor supply decision and the effects of market-clearing conditions in the labor market. We hope to address these issues in future work.
\end{abstract}

\footnotetext{
${ }^{*}$ Dept. of Economics, Williams College, Williamstown, MA 01267, david.love@williams.edu.

${ }^{\dagger}$ Federal Reserve Board, 20th and C St., NW, Washington, DC 20551, paul.a.smith@frb.gov. This research was conducted with the support of the Steven H. Sandell Grant, sponsored by the Center for Retirement Research at Boston College. We thank Margaret Lay for excellent research assistance. The views expressed herein are those of the authors and do not necessarily reflect those of the Board of Governors or the staff of the Federal Reserve System.
} 


\section{Introduction}

The ongoing transition from traditional defined benefit (DB) plans to defined contribution (DC) plans implies, among other things, a change in saving incentives and risk exposure for U.S. households. The popular media has generally seen this transition as one from a risk-free pension world to one subject to choice and uncertainty, but this obscures the fact that DB benefits are themselves prone to considerable uncertainty because of job changes, wage fluctuations, and recently, the rising incidence of pension freezes and terminations. Freezes in large healthy firms such as Verizon and IBM, as well as terminations of plans in the struggling steel and airline industries, highlight the fact that these traditional pensions cannot be viewed as risk-free promises from the employee's perspective. Indeed, the current turmoil in financial markets and difficult economic outlook for many firms suggest that many more pension plans could be frozen soon. In this preliminary paper we develop a stochastic dynamic programming model to understand how the rising risks associated with DB freezes and terminations might affect household saving decisions and expected lifetime utility.

\subsection{The Shift from DB to DC}

Traditional DB plans provide retirees with a lifetime annuity in retirement. The amount of the annuity is typically a function of the number of years of service and average or final pay. For example, a typical formula might provide a retiree with an annuity equal to 1.5 percent of final pay for each year of service. ${ }^{1}$ Since both pay and years of service increase over time, the typical formula produces a steeply increasing accrual pattern in which the bulk of the final benefit is accrued in the years just before retirement. For example, a worker with 5 years of service and "final pay" (e.g., average of the highest three years) of $\$ 25,000$ would have accrued an annuity of $5 \times \$ 25,000 \times .015=\$ 1,875$ in our model plan, while a worker with 30 years of service and final pay of $\$ 100,000$ would receive an annuity of $30 \times \$ 100,000 \times .015=\$ 45,000$. That is, while the latter worker's pay is four times higher than the former's, her annuity is 24 times larger, due to the interaction of higher pay and more years of service.

\subsubsection{Decreasing Demand from Workers}

This "back-loaded" benefit accrual pattern has the effect of rewarding workers with long tenure, and it successfully provides a stable source of retirement income for long-tenure workers. However, as shown by our example, workers with shorter tenures earn considerably

\footnotetext{
${ }^{1}$ In practice, most "final pay" plans use an average of the highest 3 or 5 years of pay. In addition, most plans cap years of service at, e.g., 30 or 35 years.
} 
less from the traditional formula. Traditional DB benefits are not "portable," in the sense that a worker who moves to a new job must start over in a new DB plan, resetting years of service to zero at each job change. As a result, a worker who changes jobs several times in her career will not acquire the long tenure necessary to accrue a significant benefit. As the labor market has become more mobile and job changes more frequent, the value of traditional DB coverage has fallen. In contrast, DC plans, which accrue savings in a taxpreferred account, are more portable across employers and provide a more linear accrual pattern, which make them relatively more valuable as job mobility increases. DC plans became increasingly popular after the introduction of section $401(\mathrm{k})$ of the tax code, which provides for a deferral of income tax on wages allocated to a DC account rather than taken as cash. These plans became particulaly popular because most employers match workers' 401(k) contributions. During the late 1990s the stock market soared and many employees (particularly younger workers) viewed $401(\mathrm{k})$ plans as an especially effective and convenient way to prepare for retirement.

\subsubsection{Increasing Costs for Firms}

At the same time that increasing job mobility and the advent of 401(k) plans were reducing workers' demand for traditional DB pensions, other forces were reducing employers' willingness to provide them. ${ }^{2}$ In 1985 the Financial Accounting Standards Board (FASB) released guidance requiring the use of a certain type of actuarial method in accounting for the accrual of pension benefits. The required method, called the projected unit credit method, accounted for pension costs as they accrued, rather than spreading them evenly over each worker's expected career. Since DB benefits accrue rapidly at the end of a career, the switch to the new method reduced funding costs for younger workers and increased them for older workers. FASB's guidance really only applied to the accounting treatment of pension plans as reported on annual statements; firms were still free to use different assumptions in calculating their required contributions. Nonetheless, many plans made conforming changes to their assumptions on the funding side. This was significant, because it meant that as baby boomers aged, pension funding costs rose quickly. As global competition increased, these higher costs became a significant drag on firms' competitiveness.

In addition to the accounting changes, tax laws also changed in the 1980s. Because employer contributions to DB funds and earnings thereon were tax-exempt, Congress added a "full-funding limit" in 1987 to limit revenue losses, a change that reduced companies' incentive to contribute to the plans. After a series of high-profile corporate takeovers in which acquirers terminated over-funded plans in order to gain access to the excess assets,

\footnotetext{
${ }^{2}$ This discussion closely follows Munnell and Soto (2007). See that paper for a more detailed exposition of the institutional history of DB plans.
} 
Congress also added a "reversion tax" of (eventually) 50 percent (in addition to ordinary corporate income tax) on excess assets reclaimed from terminated plans. Moreover, to limit the tax expenditure on high-income pension participants, Congress capped the amount of compensation that could be considered in funding pension benefits. While the cap itself was indexed for inflation, firms were not permitted to take this indexation into account when funding future benefits. All of these changes had the effect of reducing firms' incentive to fund pension benefits.

\subsubsection{Recent Developments}

When the stock market bubble burst in 2000, pension funds were hit with what came to be called "the perfect storm": stock losses reduced funds' assets significantly, while lower interest rates increased the present value of future pension payments. As a result, the funding status of many pension plans (i.e., assets relative to liabilities) deteriorated dramatically. The resulting funding gaps put unprecedented pressure on the Pension Benefit Guaranty Corporation (PBGC), the insurer of private pension plans. A number of large underfunded plans terminated in bankruptcy, resulting in record claims on the PBGC. While from 1995 to 2000 net claims on the PBGC averaged $\$ 133$ million per year, from 2001 to 2005 the average was over $\$ 4$ billion per year. From 2000 to 2004 the net position of the PBGC (assets less liabilities) plummeted from $\$ 10$ billion to $-\$ 23$ billion.

Partly in response to the funding crisis, Congress passed the Pension Protection Act of 2006, a major reform of pension rules that tightened funding requirements and moved the pension regulatory system away from actuarial or smoothed values and toward market values. About the same time, FASB announced new guidance requiring for the first time that firms recognize the net position of the pension funds on their balance sheets. ${ }^{3}$ FASB also began a longer-term project to reform the accounting of pension accruals on corporate earnings statements. This new guidance is widely expected to reduce the use of the smoothed values and require recognition of changes in the market value of the pension fund on earnings statements - potentially making earnings statements much more volatile. The combined effect of these recent developments, on top of the longer-term trends already at work, has been a significant acceleration of the retreat from DB plans among private sponsors.

The current financial crisis, and difficult economic outlook for many firms, seem likely to accelerate pension freezes. So far this year, the effect of steep stock losses on funding status has been somewhat offset by sharply higher corporate interest rates (which lead to lower calculations of pension liabilties). This offset is arguably a mirage, because the higher corporate rates do not really change the underlying economics of the pension plan's

\footnotetext{
${ }^{3}$ Previously, the assets and liabilities of the pension fund were separately disclosed in footnotes.
} 
finances, while the lower stock prices do. ${ }^{4}$ Nonetheless, the higher rates have real effects because future required contributions are calculated relative to the funding measure based on corporate rates. Regardless of the partial offset, however, it is likely that many DB plans will face significantly weakened funding positions next year, at a time when sponsoring firms are expecting difficult economic conditions of their own. In this environment, an acceleration of pension freezes seems likely. ${ }^{5}$

\subsection{Freezes and Terminations}

Firms are legally required to pay pension promises already accrued; however, they are free to modify, freeze or terminate their plans going forward. A modification could include, for example, a reduction in the accrual rate (e.g., from $1.5 \%$ per year to $1 \%$ per year), a reduction in the maximum years of service considered, etc. A freeze can take several forms, but generally involves a cessation of new accruals. A "hard freeze" eliminates all future accruals, so annuities will not grow from the level reached at the time of the freeze. A "soft freeze" typically eliminates new accruals based on years of service, but allows annuities to continue to rise based on rising earnings. A "partial freeze" freezes benefits for some workers but not others. A "closed plan" does not accept any new entrants but allows accruals for current participants. Terminations generally take one of two forms, but both involve ending the program and surrendering the pension fund. In a standard termination, the firm liquidates the fund and uses the assets to buy annuities from an insurance company in order to provide the promised benefits to each worker. Standard terminations generally require the pension to be fully funded. In a "distress termination," the firm turns the pension assets and liabilities over to the PBGC. Distress terminations are used by underfunded plans in bankrupt firms, and generally require the approval of the bankruptcy judge.

As noted above, the dollar value of distress terminations has skyrocketed since 2000, causing a severe strain on the PBGC. But freezes have also increased dramatically. A partial list of well-known firms announcing hard freezes in the past few years includes Coca Cola, Delphi, FedEx, Fidelity, Goodyear, IBM, Michelin, NASDAQ, State St Corp., Suntrust Banks, and Verizon. Soft freezes have been less common, but include Dupont, GM, and Hershey. As shown in the table below, a PBGC analysis of hard freezes found that by 2005, 14 percent of DB plans had instituted hard freezes, covering 6 percent of DB participants.

Note that this table understates freezes to the extent that it does not include soft freezes, partial freezes or closed plans. Moreover, many other firms are considering a freeze: a recent Towers Perrin survey of senior finance executives found that 48 percent of companies would

\footnotetext{
${ }^{4}$ That is, the "true" economic liabilities of the pension plan are more correctly measured by a risk-free rate.

${ }^{5}$ In addition to its previously announced DB pension freeze, last week GM announced it was temporarily suspending matching contributions in its $401(\mathrm{k})$ plans for salaried workers.
} 
freeze defined benefit plans if those plans cut into buybacks, capital spending, or other priorities. In 2006, fully 62 percent of companies were considering freezing pension plans in the face of the changing legislative and accounting environment discussed above.

Virtually all firms announcing a freeze simultaneously announced enhancements to DC benefits, typically in the form of more generous matching provisions. Thus, depending on a worker's age and the size of the enhancement relative to the DB generosity, some workers may be fully compensated or even better off after the freeze (typically younger workers), while others may be less than fully compensated (typically workers closer to retirement). This age profile in compensation changes is something that we will explore in more detail in our model of pension freezes and terminations.

\section{Previous Literature}

Because the trend toward pension freezes is so recent, the literature studying them has only recently begun. As mentioned above, the Pension Benefit Guaranty Corporation (2008) analyzes hard freezes from 2003 to 2005, finding that about 14 percent of plans are hardfrozen. They also find that small plans are more likely to freeze than large plans and that frozen plans were only about half as likely as non-frozen plans to be fully funded. By industry, manufacturing shows the highest freeze rate (about 18 percent by 2005), while financial firms showed the lowest (about 9 percent). The Government Accountability Office (2008) performed a new survey of DB plans, finding significant incidence of freezing since 2005. They find that fully 21 percent of all active (i.e., non-retired) participants are now affected by a freeze, and that half of sponsoring firms have at least one frozen plan. About 44 percent of the frozen plans are hard frozen. They find that the hard-freeze rate is significantly higher among small firms, and the freeze rate is significantly lower among collectively bargained plans.

The Employee Benefit Research Institute (2006) uses a simulation model to analyze how freezes affect workers of different ages and salary levels. They calculate the level of annual employer contribution rate to a DC plan that would fully compensate each worker in their database. They estimate a median rate of 8 percent, assuming 8 percent returns on future

DC assets. But they find a large degree of heterogeneity - even a contribution rate of 16 percent would leave a quarter of workers (mostly older) less than fully compensated.

Munnell and Soto (2007) provide a detailed historical context for the current wave of pension freezes, and then assemble a database of pension plans by merging data from Department of Labor Form 5500 reports (filed annually by private pension plans) with firmlevel data from Compustat. They find that about 15 percent of plans are frozen, and that the likelihood of a freeze is higher among firms with lower funding levels, lower credit ratings, 
and more retired participants relative to total participants (and thus higher pension costs). Beaudoin et al. (2007) use a sample of S\&P500 firms from Compustat to study the correlates of a pension freeze among a large number of firm-level financial statistics, finding that the best predictor seems to be the funding status of the plan. Finally, Rubin (2007) studies the impact of pension freezes on firm value, and the market response to freeze announcements. He finds that freezes do increase firm value but that markets lag in responding to the increase.

These papers have provided the first analysis of pension freezes and their effect on workers. Our contribution is to examine the effects of pension freezes in the context of a life-cycle model of saving. As described in the following sections, our approach is to develop a stochastic dynamic programming model to understand how the risks associated with DB freezes and terminations affect household saving and expected lifetime utility.

\section{The Model}

Our model economy builds on the work of Schrager (2006) to allow for pension freezes and terminations. ${ }^{6}$ The key innovation in our framework is that we allow for the possibility that firms shut down their defined benefit (DB) pension and replace it with a defined contribution (DC) plan. Since not all firms offer pensions and there is always the possibility of a job separation, we also consider job changes from firms with pensions to those without.

Our model individuals start working at age 20 , retire at age 65 , and live to a maximum of age 100. During the working years, they occupy one of three employment states. They can be employed by a firm offering a traditional DB pension; they can be employed by a firm offering a DC pension; or they can be employed at a firm without a pension. Under both types of pension plans, benefits vest immediately. ${ }^{7}$

The DC pension plan is characterized by an employer match rate $\mu$, a limit on employer matching contributions, $\psi$, and a statutory limit on annual employee contributions, $L .^{8}$ Ordinarily, modeling DC plans requires one to keep track of an additional continuous state

\footnotetext{
${ }^{6}$ Schrager (2006) investigates the impact of increased job turnover on the attractiveness (to employees) of DB pensions relative to DC plans. To compare the expected utility benefits associated with each pension type, Schrager models two steady-state economies: one in which individuals have access only to DB plans and another in which individuals have access only to DC plans. Because we are interested in the effects of freezes and terminations, we need to consider an economy in which both types of plans are offered. Thus one of the key distinctions in our modeling approach is to allow for transitions between firms offering DB and DC pensions.

${ }^{7}$ In practice, different vesting rules apply for $401(\mathrm{k})$ plans and DB pensions. Modeling vesting durations greatly complicates the numerical solution to the problem since it requires keeping track of both vested and unvested benefits in DB and DC plans.

${ }^{8}$ The modal $401(\mathrm{k})$ employer matching arrangement is a $50 \%$ match up to $6 \%$ of employee salary (Costo, 2006). The legal limit on employee contributions in 2008 is $\$ 15,500$ (with an additional $\$ 5,000$ of catch-up contributions for employees aged 50 and older).
} 
variable for accumulated savings in the retirement account. ${ }^{9}$ The additional state variable is particularly expensive in our modeling framework since we allow individuals to have accumulated benefits in both DB and DC pension plans. We can reduce the dimension of the computational problem from three continuous state variables (conventional saving, DC savings, and DB benefits) to two by calculating the annuity value of DC accruals and adding them to accrued DB benefits. We avoid the need to carry permanent income as a separate state variable by normalizing the other state variables to permanent income.

We convert DC balances into an actuarially fair annuity using a price that depends on the beneficiary's age and gender. We use a pre-tax interest rate because DC contributions accrue tax-free under current law. ${ }^{10}$ Thus we define the annuity value of a DC contribution as $\left.\phi_{t} Y_{t}+\mu \min \left[\phi_{t}, \psi\right] Y_{t}\right) / Q_{t}$, where the first term represents the employee's contribution rate times income, and the second term represents the employer's match rate times the lesser of the employee's contribution and the matching limit. We divide by the annuity price $Q_{t}$ in order to convert the total DC contributions into an annuity that starts payments at age 65 .

We model the DB accrual using a standard formula linking benefits to years of service at the firm $d_{t}$, final permanent income $P_{t},{ }^{11}$ and a benefit accrual rate $\alpha$. We define the real value of the $\mathrm{DB}$ annuity as $\alpha d_{t} P_{t} /(1+\pi)^{65-t}$, where $\pi$ is the economy-wide inflation rate. Most private DB plans are not adjusted for inflation, making the declining real value of pension accruals before retirement an important cost of pension freezes and terminations. Nonetheless, for computational simplicitly, we model DB payments in retirement as real annuities (i.e., fixed in real terms). ${ }^{12}$

Individuals in our model select a level of consumption $C_{t}$ and (if they are employed at a firm offering a DC pension) a contribution rate $\phi_{t}$, to maximize expected discounted lifetime utility. The value function describing the individual's problem is given by:

$$
V\left(X_{t}, P_{t}, A_{t}\right)=\max _{C_{t}, \phi_{t}}\left\{u\left(C_{t}\right)+S_{t} \beta \mathbf{E}_{t} V\left(X_{t+1}, P_{t+1}, A_{t+1}\right)+\left(1-S_{t}\right) B\left(X_{t}\right)\right\}
$$

such that

$$
X_{t}=R^{\tau}\left(X_{t-1}-C_{t-1}\right)+\left(1-\tau_{y}\right)\left(1-\phi_{t}\right) Y_{t},
$$

\footnotetext{
${ }^{9}$ See, e.g., Engen et al. (1994), Laibson et al. (1998), and Love (2006).

${ }^{10}$ Note that the pre-tax interest rate is higher than the after-tax rate, and thus leads to a lower annuity price. See Brown and Poterba (2000) for the present value formula for the price of an actuarially fair annuity.

${ }^{11}$ We make the DB formula depend on final permanent income, rather just income, because DB formulas generally take an average of either the last few years of salary or the highest few years of salary. If we made the DB formula depend on final income, $Y_{t}$, we would overstate the riskiness of DB benefits attributable to transitory fluctuations in earnings (i.e., $\Theta_{t}$ shocks).

${ }^{12}$ Given the infrequency of COLAs in private pension plans, it would be more accurate to model a nominal pension benefit stream in retirement as well. Assuming a real stream of retirement income, however, greatly simplifies the solution of the model since we do not need to keep track of separate variables for DB benefits, DC benefits, and Social Security; since all pay a real stream of income in our model, all can be modeled as a combined single stream.
} 
and

$$
A_{t}=\left\{\begin{array}{cl}
A_{t-1} & \text { if employee does not have a pension } \\
A_{t-1}+\left(\phi_{t} Y_{t}+\mu \min \left[\phi_{t}, \psi\right] Y_{t}\right) / Q_{t} & \text { if employee has a DC pension } \\
A_{t-1}+(1+\pi)^{t-65} \alpha\left[d_{t} P_{t}-d_{t-1} P_{t-1} /(1+\pi)\right] & \text { if employee has a DB pension }
\end{array}\right.
$$

where $P_{t}$ is permanent income, $R^{\tau}=1+\left(1-\tau_{r}\right) r_{t}$ is the after-tax interest rate, $S_{t}$ is the conditional survival probability, $u($.$) is an iso-elastic period utility function, B($.$) is$ an iso-elastic bequest function, and $\tau_{r}$ and $\tau_{y}$ are the tax rates on returns and income, respectively. We assume that individuals can obtain annuities only through their employerprovided pension plans. ${ }^{13}$ Because DC contributions are tax-deferred, a contribution of $\phi_{t}$ generates an after-tax income of $\left(1-\phi_{t}\right)\left(1-\tau_{y}\right) Y_{t}{ }^{14}$

Following Carroll (1992), we decompose the error process of income into a permanent component $N_{t}$ and a transitory component $\Theta_{t}$. Income in period $t$ is equal to permanent income multiplied by the transitory shock:

$$
\begin{aligned}
Y_{t+1} & =P_{t+1} \Theta_{t+1} \\
P_{t+1} & =G_{t+1} P_{t} N_{t+1},
\end{aligned}
$$

where $G$ is the trend growth rate of permanent income, and $N$ and $\Theta$ are lognormally distributed: $\ln \left(N_{t}\right) \sim \mathcal{N}\left(-\sigma_{n}^{2} / 2, \sigma_{n}^{2}\right)$ and $\ln \left(\Theta_{t}\right) \sim \mathcal{N}\left(-\sigma_{\theta}^{2} / 2, \sigma_{\theta}^{2}\right)$. The unit root process on income allows us to normalize by the level of permanent income, greatly simplifying the computational problem.

\subsection{Solving for consumption}

Using lower-case variables to denote the normalization by permanent income (e.g., $x_{t}=$ $\left.X_{t} / P_{t}\right)$, we can write the first order condition for consumption as:

$u^{\prime}\left(c_{t}\right)=\beta R^{\tau}\left[S_{t} \mathbf{E}_{t} u^{\prime}\left(\Gamma_{t+1} \mathbf{c}_{t+1}\left(R^{\tau} a_{t} / \Gamma_{t+1}+\left(1-\tau_{y}\right)\left(1-\phi_{t+1}^{*}\right) \Theta_{t+1}\right)+\left(1-S_{t}\right) \mathbf{E}_{t} B^{\prime}\left(R^{\tau} w_{t}\right)\right]\right.$,

where $w_{t}=x_{t}-c_{t}$ is end-of-period saving, $\mathbf{c}_{t+1}($.$) is the decision rule for consumption$ in period $t+1, \phi_{t+1}^{*}$ is the optimal choice of DC contributions, $\Gamma_{t}=N_{t} G_{t}$ is the growth rate of permanent income, and expectations are taken over the employment states (DC, DB, or none) and transitory and permanent income. We follow Carroll (2007) and apply the method of endogenous grid points to solve for the optimal consumption decision rules.

\footnotetext{
${ }^{13}$ In reality, private annuity markets are thin, with very low rates of participation (Benitez-Silva, 2003). Because firms can take advantage of group annuity pricing, it is reasonable to assume that actuarially fair annuities are only available through firms and Social Security.

${ }^{14}$ That is, the interaction term $\phi \tau$ is not subtracted from income.
} 
Given a list of $a_{t}$ points, we can solve the first order condition in equation (6) to find a decision rule for consumption in terms of end-of-period saving, $a_{t}$, which we can use, in turn, to recover the endogenous level of cash-on-hand through the identity $x_{t}=w_{t}+c_{t}$.

\subsection{Solving for DC contributions}

The first order condition for consumption assumes that we know the optimal value of DC contributions, $\phi_{t+1}^{*}$. One drawback of the cash-on-hand formulation of the problem is that there is no distinction between savings and income, since both are rolled together in the definition of cash on hand. Since DC contributions are expressed as a fraction of current income, the inability to separate income and savings means that we have to adopt an alternative approach to solving for optimal contributions (as opposed to the usual firstorder condition for saving). Our method asks, for a given level of end-of-period savings $w_{t}$, what the optimal contribution would be for each independent realization of the transitory and permanent shocks. Suppose that we have an interpolated value function $\hat{v}\left(x_{t}, a_{t}\right)$, where $a_{t}$ is the normalized level of the pension annuity. For each combination of discrete end-ofperiod savings $w_{i}$, annuity $a_{j}$, transitory shock $\Theta_{k}$, and permanent shock $N_{l}$, we can solve for the contribution rate $\phi^{*}(i, j, k, l)$ that maximizes the interpolated value function:

$$
\phi^{*}(i, j, k, l)=\underset{\phi}{\operatorname{argmax}} \hat{v}\left(\frac{w_{i} R}{G N_{l}}+\left(1-\tau_{y}\right)(1-\phi) \Theta_{k}, \frac{a_{j} R}{G N_{l}}+\frac{\Theta_{k}}{Q}(\phi+\min (\phi, \psi) \mu)\right),
$$

where $Q$ is the price of an actuarially fair annuity. The first term inside the interpolated value function is the remaining cash on hand after contributing $\phi \times 100$ percent of income to the DC account. The second term is the resulting size of the retirement annuity: the incoming value plus the annuity value of the employee and employer contributions to the DC plan.

In each period $t$, we solve for the decision rules for contributions $\phi$, which tell us the optimal level of contributions for any discrete combination of $w_{t}, a_{t}, \Theta_{t+1}$, and $N_{t+1}$. Substituting these values of $\phi^{*}$ into the expected decision rule in equation (6), we can then solve for the optimal level of period- $t$ consumption. Thus for a given set of discrete values for $w_{t}, a_{t}$, and $d_{t}$ (job tenure), we can solve for the optimal policy rules for $c_{t}$ and $\phi_{t}$ for each of our three employment states.

\section{Calibration and parameterization}

We use our modeling framework to approximate the welfare consequences of DB freezes and terminations. In order to take the quantitative predictions seriously, it is important to calibrate the model's parameters to match, at least approximately, empirical evidence on 
income, assets, and job separations.

\subsection{Income Process}

As is common in the life-cycle consumption literature, we estimate the income process during the working years using panel data from the PSID (the 1980-2003 waves). We take a broad definition of household non-asset income that sums labor income, public transfers (including Social Security retirement benefits, SSI, food stamps, unemployment benefits, and welfare benefits), and private transfers (e.g., child support and income receipts from non-household members), net of federal and state income taxes. We drop the low-income SEO oversample in the PSID and restrict our sample to households with male heads aged 20 to 65 with positive post-government income.

For each of three education groups (less than high school, high school, and college), we estimate separate fixed effects regressions of the natural logarithm of income on a full set of age dummies, a variable for family size, and a control for marital status. ${ }^{15}$ As is standard (see, e.g., Cocco et al. (2005)), we estimate the income profiles for each education group by fitting third-order polynomials through the estimated age-dummy coefficients and use the fixed-effects residuals to estimate the transitory and permanent components of the error process following the procedure in Carroll and Samwick (1997). The results, reported in Table 2, indicate that income follows a hump-shaped process, with college graduates showing the steepest income gradients.

\subsection{Retirement Income}

In retirement, we assume that Social Security benefits replace 41 percent of income for high school graduates and 34 percent of income for college graduates, in line with the estimates for medium and high earners reported in Table VI.F10 of The 2008 Annual Report of the Board of Trustees of the Federal Old-Age and Survivors Insurance and Federal Disability Insurance Trust Funds. ${ }^{16}$ Although our model assumes that individuals receive a constant stream of real income in retirement, we recognize that this understates the risks facing older households due to inflation (most DB plans are not cost-of-living adjusted), out-of-pocket medical cost (see, e.g., Palumbo (1999), De Nardi et al. (2006), French (2005), and Love et al. (2008)), financial risk, and family shocks due to the unexpected death of a spouse. We ignore many of these potentially interesting sources of resource uncertainty because our current focus is on the tradeoffs between DB and DC plans during the working portion of life. In addition, because we assume that DC contributions are immediately converted into

\footnotetext{
${ }^{15}$ Because the income profiles and simulated life histories of high school graduates and high school dropouts look quite similar, we focus our results on high school and college graduates.

${ }^{16} \mathrm{~A}$ PDF version of the report can be found at: http://www.ssa.gov/OACT/TR/TR08/tr08.pdf .
} 
a retirement annuity, we have effectively assumed away one of key differences between DB and DC accounts - the tradeoff between the insurance provided by a a DB annuity and the ability to drawdown a large portion of savings to finance a sudden medical expense shock. ${ }^{17}$

\subsection{Preferences}

For preferences, we adopt constant relative risk aversion functions for both utility and bequests, such that:

$$
u\left(C_{t}\right)=\frac{C_{t}^{1-\rho}}{1-\rho}
$$

and

$$
B\left(X_{t}\right)=\frac{b}{1-\rho}\left(\frac{X_{t}}{b}\right)^{1-\rho},
$$

where $b$ is a parameter determining the curvature of the marginal bequest function. For the baseline results reported in the paper, we assume a value of $\rho=3$ for the coefficient of relative risk aversion and set the bequest parameter to 0 .

\subsection{Transition Probabilities}

In addition to income and preferences, we also need to choose values for the transition matrix governing movements between employment states - i.e., the probabilities of job separations and pension freezes. Further, since one of the focuses of this paper is on the transition from a low-freeze-probability environment to a high-freeze-probability environment, we specify a separate set of transition probabilities for each environment. The Markov chain we specify for the transition probabilities is meant to be only a rough approximation of the employment risks faced by a typical employee. While it does not allow separation probabilities to depend on important characteristics such as age, job tenure, gender, or education, it does capture the key features of our modeling framework. In each period, individuals in a DB firm face two risks: they may experience a pension freeze (with a replacement DC plan) or they may experience a transition to a "bad" job that offers no pension at all. ${ }^{18}$ We assume that

\footnotetext{
${ }^{17}$ To test the importance of medical expense risk, we also solve the model allowing for both permanent and transitory fluctuations in retirement income due to out-of-pocket medical expenses. We estimated the variance process for retirement income net of medical costs using data on income and medical costs from the 1992-2006 waves of the HRS (see Appendix for details). The most salient change induced by the presence of income risk in retirement is a pronounced increased in the average level of cash on hand heading into retirement and a markedly more gradual rate of wealth drawdown that reflects a strengthened precautionary saving motive. Since we can obtain the same level of wealth accumulation by adjusting other parameters in the model such as risk aversion and the discount factor, we decided to keep our results focused on the more transparent (from a modeling perspective) case of constant retirement income.

${ }^{18}$ This possibility, which involves a drop in compensation, is included to capture the idea that some workers may have firm-specific human capital at stake in the event of job loss.
} 
workers in jobs with DC plans will never experience a pension "thaw" - a transition from a DC plan to an unfrozen DB plan — but that they still face a probability of job separation. ${ }^{19}$

In the low freeze probability environment, we specify the following transition matrix:

$$
\Pi_{i, j}=\left(\begin{array}{ccc}
0.97 & 0.00 & 0.03 \\
0.01 & 0.96 & 0.03 \\
0.10 & 0.25 & 0.65
\end{array}\right)
$$

where $i, j \in\{$ DC plan, DB plan, No plan $\}$. That is, a worker in a DB firm (second row) faces a $1 \%$ freeze probability (first column) and a $3 \%$ job loss probability (third column).

In the high freeze probability environment, we assume the transition matrix is:

$$
\Pi_{i, j}=\left(\begin{array}{ccc}
0.97 & 0.00 & 0.03 \\
0.05 & 0.92 & 0.03 \\
0.10 & 0.25 & 0.65
\end{array}\right) .
$$

Thus, in this environment, workers in DB firms face a freeze probability of $5 \%$. The lowfreeze $(1 \%)$ and high-freeze (5\%) probabilities are roughly consistent with the pre-2001 and post-2001 incidences of DB freezes documented in Government Accountability Office (2008).

\subsection{Pension Generosity}

Empirically, most DB freezes are accompanied by enhancements to DC plans - typically more generous matching provisions. We assume that firms offering DC pensions match contributions up to 6 percent of salary. In our baseline simulation, we assume that DC firms offer the modal match in the data of 50 percent (Munnell and Sunden, 2004). To capture the idea of enhanced DC generosity in the event of a pension freeze, we also calibrate a match that fully compensates workers in the aggregate - i.e., we choose the match rate that causes the firm to incur the same expected annual pension costs as the prior DB plan. ${ }^{20}$ To implement this, we assume a uniform age distribution of workers (normalized to one worker per age), and specify the annual pension costs under a DC plan in which workers contribute to the employer matching limit as:

$$
\mu \psi \sum_{i=20}^{64} Y_{t} .
$$

The annual costs under the DB plan are slightly more complicated. Let $Q_{t}$ be the annuity price for an individual aged $t$, and let $d_{t}$ be her tenure. The expected annual costs of the

\footnotetext{
${ }^{19}$ This is consistent with empirical evidence - e.g., see Government Accountability Office (2008).

${ }^{20}$ Note that this does not ensure that each worker is fully compensated. We will return to this crucial distinction below.
} 
DB plan are then given by:

$$
\alpha(1+\pi)^{20-65} P_{20} Q_{20}+\alpha \mathbf{E}_{20} \sum_{t=21}^{64}(1+\pi)^{t-65}\left[d_{t} P_{t} Q_{t}-d_{t-1} P_{t-1} Q_{t-1} /(1+\pi)\right] .
$$

An easy way to interpret the annual DB costs in the equation above is to note that the first term is the cost of funding the accrued pension of a 20-year-old worker. The second term inside the summation then represents the incremental increase in pension costs for older workers, consisting of a tenure component (the $d_{t}$ terms) and an income component. ${ }^{21}$ As a baseline assumption, we set the DB benefit fraction $\alpha=0.015$, which is the most popular generosity factor per year of service in the National Benefits Survey (see Schrager (2006)). We solve for the match rate $\mu$ that equates the annual pension costs in equations (12) and $(13) .^{22}$

\section{Simulation results}

With our approximated decision rules in hand, we simulate 20,000 independent life histories that vary by income realizations and employment. We initialize our model economy by assuming that $50 \%$ of workers start out in a non-pension firm, $25 \%$ start out in a firm offering a DC pension, and $25 \%$ start out in a firm offering a DB pension. All individuals begin the working life with the same trend income but experience different realizations of shocks to transitory and permanent income.

The simulations allow us to describe the optimal saving decisions and welfare implications for the "typical" household in terms of savings, employment, and pension benefits. We begin our analysis of the simulation results by taking a brief look at the average life cycle paths implied by our model parameterization. For the baseline specification (DC matching rate of $50 \%$ up to $6 \%$ of salary and a DB generosity factor of $1.5 \%$ ), Figure 1 displays the average simulated profiles of consumption, cash on hand, income, and the retirement annuity for both high school and college graduates.

\footnotetext{
${ }^{21}$ Our estimated income profiles give us the expected values of permanent income, $\mathbf{E}_{20} P_{t}$. Obtaining the expected values of $d_{t}$ requires slightly more work. Here we use 20,000 Monte Carlo simulations of our employment transition matrix to find the average tenures at each age $t$. As in our model simulations, we initialize the process assuming that 25 percent of the population have a DB plan, 25 percent have a DC plan, and 50 percent are employed in a firm that does not offer a pension.

${ }^{22}$ Note that taxes do not enter the annual cost calculations. Since both employer contributions to DC and DB plans receive the same tax advantage under the tax code, we can cancel the tax terms in each equation.
} 


\subsection{Cash on Hand}

The trajectory of cash on hand follows the conventional accumulation pattern, hewing closely to income during the early working years when households are likely to be credit constrained and then rising rapidly to a peak at retirement. College graduates, who have steeper and more hump-shaped income profiles, appear to be credit constrained for much longer than high school graduates - a result that has been been found in previous life-cycle studies (see, e.g., Zeldes (1989) and Hubbard et al. (1995)). ${ }^{23}$

\subsection{Retirement Wealth}

Another interesting feature is the relationship between income and the retirement annuity. At the beginning of the working years, the average level of the retirement annuity barely rises above zero, reflecting both the low levels of employee DC contributions at these ages (despite the generous matching provisions, the credit constraints cause younger households to defer making contributions until income rises above a threshold amount) as well as the structure of the DB formula, which implies a nonlinear growth in pension benefits with respect to years of service. Although the retirement annuity accumulates during the working years, it does not generate income until retirement. Thus, the average income profiles from age 20 to 64 are essentially the same as the estimated income profiles from the PSID. At retirement, however, permanent income includes both the retirement annuity as well as the Social Security replacement rate. On net, the average simulations show that the total replacement rate of income in retirement is close to $100 \% .^{24}$

\subsection{Effect of Pension Freezes}

A key question about the transition from DB to DC plans is how the welfare consequences of the transition are borne by employees of different ages. In a classical labor market with neither firm-specific human capital nor search frictions, total compensation (wages plus benefits) must deliver the same reservation utility value, regardless of the structure of

\footnotetext{
${ }^{23}$ The simulated levels of cash on hand for the two education groups are lower than the wealth holdings in the PSID. According to the 1999-2005 wealth supplements in the PSID, median cash on hand (defined as net wealth plus current income) for married high school graduates is around $\$ 300,000$ for married couples and around $\$ 200,000$ for single males (in 2006 CPI-U-adjusted dollars). For college graduates, the median level of cash on hand is around $\$ 550,000$ for married couples and $\$ 300,000$ for single males. The simulations in Figure 1 show roughly half as much cash on hand. It is not surprising, however, that our model understates wealth accumulation since we assume that all DC savings are annuitized.

${ }^{24}$ This might seem to be an optimistic view of retirement savings relative to what we observe in the data. Munnell and Soto (2005), for instance, estimate median replacement rates in the HRS of about 79 percent for married couples and about 89 percent for single-headed households. Once we account for the fact that we are annuitizing $100 \%$ of DC contributions, however, the higher replacement rates seem less out of line with their empirical counterparts.
} 
compensation. In that world, pension freezes and terminations would be wholly irrelevant except to the extent that they signaled a change in the market clearing level of compensation. In our model, we are implicitly assuming that some combination of search frictions and firmspecific human capital provides firms with the ability to change total compensation without losing workers.

Higher probabilities of pension freezes may be viewed as good or bad news from the standpoint of the representative employees in our model. Younger workers, for instance, have more to gain from a shift from a DB to DC plan than older workers. Not only do they have more years to contribute to the plan, but their lower average years of service mean that they have less at stake in terms of foregone DB benefits. Thus, we analyze the welfare consequences of a pension freeze by age.

We target our simulation exercises to answer two basic questions about the transition from DB to DC plans. First, for different ages and tenures, what are the welfare consequences of a realized pension freeze - that is, what would be the required additional compensation to make an employee indifferent toward a DB pension freeze? And second, what are the welfare consequences of an increase in the risk of a pension freeze, even among those who do not experience one?

\subsection{Welfare measure}

Our measure of the change in welfare is a compensating variation notion. Let $\hat{v}_{D B}^{l o w}\left(x_{t}, a_{t}, d_{t}\right)$ and $\hat{v}_{D B}^{h i g h}\left(x_{t}, a_{t}, d_{t}\right)$ be the interpolated value functions for individuals in a firm with a DB pension under either a low freeze probability or a high freeze probability environment. We can solve for the change in cash on hand (normalized by permanent income), $\Delta_{t}^{\text {trans }}$, such that the individual is indifferent between the two environments. That is:

$$
\hat{v}_{D B}^{l o w}\left(x_{t}, a_{t}, d_{t}\right)=\hat{v}_{D B}^{h i g h}\left(x_{t}+\Delta_{t}^{\text {trans }}, a_{t}, d_{t}\right) .
$$

Using a root-finder to solve for $\Delta_{t}^{\text {trans }}$ for each simulated individual with a DB plan, we can then compute the average welfare compensating variation, $\bar{\Delta}_{t}^{\text {trans }}$, for each age during the working portion of the life cycle. The interpretation of $\bar{\Delta}_{t}^{\text {trans }}$ is that it represents the average amount of additional wealth individuals aged $t$ would need to receive to compensate them for a shift in the transition probabilities occurring.

We can apply a similar technique to compute the compensating variations for realized pension freezes occurring in either a high or a low freeze-probability environment. For example, the welfare measure for a freeze in a low probability environment, $\Delta_{t}^{\text {low }}$, would be given implicitly by:

$$
\hat{v}_{D B}^{l o w}\left(x_{t}, a_{t}, d_{t}\right)=\hat{v}_{D C}^{l o w}\left(x_{t}+\Delta_{t}^{l o w}, a_{t}\right)
$$


We can again average over individuals with a DB plan for each age $t$ and calculate the average compensation $\bar{\Delta}_{t}^{\text {low }}$. Following the same strategy, we can compute $\bar{\Delta}_{t}^{\text {high }}$ for individuals in a high probability environment. Together, the values of $\bar{\Delta}_{t}^{\text {trans }}, \bar{\Delta}_{t}^{\text {low }}$, and $\bar{\Delta}_{t}^{\text {high }}$ tell us how the typical simulated DB participant would fare under either a change in the economy-wide probability of freezes or, more directly, under an actual pension freeze that replaces a DB plan with a DC plan.

\subsection{Welfare Results}

\subsubsection{Welfare Costs of a Realized Pension Freeze}

Figure 2 shows how the compensating variations for a realized pension freeze change with the age of the employee. The left age profile shows the welfare measure for high school graduates, and the right age profile shows the results for college graduates. Since the welfare costs of a freeze depend on the expectations of such an event (i.e., the freeze probabilities), we plot two different profiles for each education group: one that represents the welfare costs of a sudden freeze for each age under a low freeze probability environment (probability = $1 \%$ ) and one that represents the welfare costs under a high freeze probability environment (probability $=5 \%$ ).

The age profile for high school graduates indicates that the welfare costs of a freeze follows a hump-shaped path over the working portion of the life cycle, with a peak at around $\$ 6,000$ for the low probability environment and around $\$ 5,000$ for the high probability environment. Intuitively, the more likely a freeze is, the less costly the realization of the event. The hump-shaped pattern primarily reflects the accrual formula of the DB plan. Early in the life cycle, average years of service are low, and less DB benefits are at stake in the event of a freeze. Later, as average tenures lengthen and incomes rise (both of which generate increases in DB benefits), the welfare costs of shifting to a DC plan become more severe. After a certain point, around age 55, incomes taper off, leaving less DB benefits on the table in the event of a freeze. Welfare costs therefore tend to decline in the last 10 years or so before retirement. Note that the welfare costs of a freeze are always positive for both high school and college graduates. We generate this result with the baseline model because a DC plan with a $50 \%$ match is strictly dominated by a DB plan with a $1.5 \%$ generosity factor.

College graduates have a slightly different pattern of welfare costs due to pension freezes. Just as with high school graduates, average welfare costs reach a maximum near age 55, but they do not rise monotonically throughout the working life. Instead, there is an initial increase to about age 35, then a slight drop, and then an acceleration to the age-55 peak. This occurs because early in the life cycle, when households are credit-constrained and the 
marginal utility of consumption is high, DB accruals are low relative to what optimal DC saving would be. In other words, young households benefit from the back-loaded nature of DB plans in that they allow young workers to consume more when their marginal utility of consumption is relatively high. Thus college graduates, who are severely credit-constrained for the first decade of the working life, find freezes particularly costly since they force the worker to switch to a DC plan and thus reduce consumption further in order to accumulate sufficient retirement resources. After age 35 or so, college graduates are no longer credit constrained, and the DC plan becomes an increasingly attractive vehicle for retirement saving. For a while, these benefits lead to a reduction in the welfare costs associated with a freeze until, eventually, the service and income parts of the DB formula again make DCs increasingly costly to the worker.

Note that even though college graduates have higher average earnings than high school graduates, they show a lower average welfare cost - in absolute terms. The explanation for this resides in the lower Social Security replacement rates experience by college graduates relative to high-school graduates. College graduates save more because they expect a much sharper decline in income in retirement and thus have a stronger incentive to build up wealth either through both conventional saving and DC contributions. Thus, college graduates who experience a freeze can add to their saving by substituting from conventional saving to DC contributions. High school graduates, in contrast, may have to significantly reduce their consumption to take advantage of the more generous matching contributions after the freeze. ${ }^{25}$

\subsubsection{Welfare Costs of a Higher Freeze Probabilities}

The rapid acceleration of pension freezes and terminations in the last 10 years raises the question of how costly this transition in the freeze probabilities has been for the typical employee with a DB plan. That is, even without experiencing a freeze directly, an employee might still experience a significant decrease in welfare because of the decrease in the expected value of pension benefits. Figure 3 examines the welfare consequences of a shift in the probability of a freeze from $1 \%$, which corresponds to the pre-2000s environment, to a probability of $5 \%$, which is in line with the probabilities implied by the spate of pension freezes in the early 2000s. The shapes of the profiles for high school and college gradates look quite similar to the profiles in Figure 2, with welfare costs between a fifth and a quarter as large.

As a final set of welfare experiments, we also investigate the implications of pension

\footnotetext{
${ }^{25}$ The issue of asset substitution is central to the debate on whether 401(k) plans actually create new national saving. For a discussion of the importance of asset substitution in DC plans, see Engen et al. (1996).
} 
freezes and an economy-wide transition in the probability of pension freezes for the case in which firms replace DB plans with a DC plan that costs the same expected amount annually. Figure 4 displays the simulated profiles of welfare costs of pension freezes for high school and college graduates. In contrast to the previous experiment with a DC matching rate of $50 \%$, the higher implied matching rate in these versions of the model, make the DC plan the preferred savings vehicle for younger high school graduates and for almost all ages for college graduates. The pattern, though is similar. The DC plan is most attractive at the point where households would like to build up wealth for retirement and relatively less at older ages, when the DB formula implies large gains due to tenure and wage growth. Younger college graduates gain as much as $\$ 12,000$ in compensating variation terms from pension freezes with the higher matching rate (over 100\%), while high school graduates show a much smaller change. Again, the difference has to do with the difference in the saving incentives implied by the age profiles of earnings and the Social Security replacement rates. College graduates have a stronger incentive to save in order to supplement pension and Social Security income and therefore benefit disproportionately from the shift to the DC plan.

\section{Important Omissions Left for Future Work}

This paper takes a preliminary look at the welfare consequences of the recent increase in DB pension freezes and terminations. The welfare consequences are computed from simulations of a life-cycle model that allows for employment transitions among firms offering DB plans, DC plans, or no pension plan at all. The baseline simulations indicate that the costs of pension freezes are relatively modest when the DB pension is replaced by a DC plan with a match rate of 50 percent or more. High school graduates, for instance, would require an average of at most about $\$ 6,000$ in additional cash on hand to compensate them for a pension freeze. College graduates would require only about a third as much. In addition, when we set the DC employer matching rate in such a way that the firm's annual pension costs remain roughly the same, we find that younger high school graduates and college graduates of all ages would actually benefit from a pension freeze.

This work is preliminary. In trying to characterize the welfare consequences of pension freezes and terminations, we have made a number of modeling decisions that could limit the empirical validity of our simulations. Some of these compromises are unlikely to have a large effect on the basic message of our paper-namely that the welfare costs associated with pension freezes are relatively small - but others are likely to have a first-order impact on our results. The two most important omissions, in our view, are the absence of a labor supply decision and the violation of market-clearing compensation. 
Labor supply matters in a couple of respects. First, because the DB pension formula is linked to years of service, employees who may have experienced shocks to income during the working years have an incentive to stay with the firm to accumulate additional savings and benefits. Of course, firms are aware of this incentive and generally structure their benefit formulas to encourage normal-age retirement. But even still, labor supply constitutes an essential margin of adjustment that can limit the welfare consequences of events such as pension freezes and terminations.

In terms of the labor market, a more fundamental issue is that our modeling framework violates a market-clearing condition. As Bulow (1982) has pointed out in the context of measuring pension liabilities, salary and pension benefits should be consistent with the instantaneous marginal product of labor in each year of an employee's service at the firm. If the value of compensation were to fall below the market clearing condition, the employee would leave for another firm. If the value of compensation were too high, the firm would be overpaying relative to the market and thus run negative profits. In our model, this competitive labor market condition would imply that employees would face, in expectation, zero change in the utility value of compensation when a firm freezes its pension.

In contrast to the competitive labor market condition, Ippolito (1985a,b) has argued that DB pension represent an implicit contract between the firm and the employee, with firms underpaying relative to the marginal product in early years and overpaying relative to the marginal product in later years. This assumption would allow for an effect from a pension freeze in our model; however, it raises the question why the firm would suddenly decide to restructure the age pattern of compensation by freezing its pension. Might it reflect an age bias (presumably toward the young) in the distribution of skill-based technical change? If so, then the real story is less about pension freezes and more about the nature of this change in the age composition of productivity shocks. Alternatively, the age tilt in the compensation pattern of DBs may reflect a bargaining agreement between unions and managers. But if this is the case, then the locus of the issue is again not so much the pension freeze per se, but instead the weakening of union bargaining power at the expense of older workers.

Finally, because pension freezes are a relatively recent phenomenon, it is difficult to know whether we are right in modeling the transition as movement from one low-probability steady state to another, higher-probability steady state. If the freezes are actually symptoms of the broader decline and possible extinction of DB plans, then the expected probabilities may indeed by increasing over time. 


\section{References}

Beaudoin, Cathy, Nandini Chandar, and Edward M. Werner, "An Empirical Investigation of the Defined Benefit Pension Freeze Decision," 2007. Working Paper.

Benitez-Silva, Hugo, "The Annuity Puzzle Revisited," June 2003. Michigan Retirement Research Center Working Paper.

Brown, Jeffrey R. and James M. Poterba, "Joint Life Annuities and Annuity Demand by Married Couples," The Journal of Risk and Insurance, 2000, 67 (4), 527-553.

Bulow, Jeremy, "What Are Corporate Pension Liabilities?," Quarterly Journal of Economics, 1982, 97, 435-452.

Carroll, Christopher D., "The Buffer-Stock Theory of Saving: Some Macroeconomic Evidence," Brookings Papers on Economic Activity, 1992, 1992 (2), 61-156.

_ , "Lecture Notes on Solution Methods for Microeconomic Dynamic Stochastic Optimization Problems," August 2007. Lecture Notes.

- and Andrew A. Samwick, "The Nature of Precautionary Wealth," The Journal of Monetary Economics, 1997, 40 (41-71).

Cocco, Joao F., Francisco J. Gomes, and Pascal J. Maenhout, "Consumption and Portfolio Choice over the Life Cycle," The Review of Financial Studies, 2005, 18 (2), 491-533.

Costo, Stephanie L., "Trends in Retirement Plan Coverage over the Last Decade," Monthly Labor Review, 2006.

De Nardi, Mariacristina, Eric French, and John Baliey Jones, "Differential Mortality, Uncertain Medical Expenses, and the Saving of Elderly Singles," November 2006. Manuscript.

Employee Benefit Research Institute, "Defined Benefit Plan Freezes: Who's Affected, How Much, and Replacing Lost Accurals," 2006. Issue Brief \# 291.

Engen, Eric M., William G. Gale, and John Karl Scholz, "Do Saving Incentives Work?," Brookings Papers on Economic Activity, 1994, 1994 (1), 85-180.

_ , _ , and _ , "The Illusory Effects of Saving Incentives on Saving," The Journal of Economic Perspectives, Autumn 1996, 10 (4), 113-138.

French, Eric, "The Effects of Health, Wealth, and Wages on Labor Supply and Retirement," Review of Economic Studies, 2005, 72, 395-427.

Government Accountability Office, "Defined Benefit Pensions: Plan Freezes Affect Millions of Participants and May Pose Retirement Income Challenges," 2008. Washington, DC. 
Hubbard, R. Glenn, Jonathan Skinner, and Stephen P. Zeldes, "Precautionary Saving and Social Insurance," Journal of Political Economy, Apr. 1995, 103 (2), 360399.

Ippolito, Richard, "The Economic Function of Underfunded Pension Liabilities," Journal of Law and Economics, 1985, 28 (3), 611-51.

_ , "The Labor Contract and True Economic Pension Liabilities," American Economic Review, 1985, 75 (5), 1031-43.

Laibson, David I., Andrea Repetto, and Jeremy Tobacman, "Self-Control and Saving for Retirement," Brookings Papers on Economic Activity, 1998, 1998 (1), 91-196.

Love, David A., "Buffer Stock Saving in Retirement Accounts," Journal of Monetary Economics, 2006, 53 (7), 1473-1492.

_, Paul A. Smith, and Michael G. Palumbo, "The Trajectory of Wealth in Retirement," The Journal of Public Economics, 2008, forthcoming.

Munnell, Alicia H. and Annika Sunden, Coming up Short: The Challenge of 401(k) Plans, Washington, DC: Brookings Institution Press, 2004.

_ and Mauricio Soto, "What Replacement Rates Do Households Actually Experience in Retirement?," August 2005. Center for Retirement Research WP 2005-10.

_ and _, "Why are Companies Freezing Their Pensions?," 2007. Center for Retirement Research Paper 2007-22.

_, Francesca Golub-Sass, Mauricio Soto, and Francis Vitagliano, "Why Are Healthy Employers Freezing Their Pensions?," An Issue in Brief, CRR, March 2006, 44.

Palumbo, Michael G., "Uncertain Medical Expenses and Precautionary Saving Near the End of the Life Cycle," Review of Economic Studies, Apr. 1999, 66 (2), 395-421.

Pension Benefit Guaranty Corporation, "Hard Frozen Defined Benefit Plans," 2008. Washington, DC.

Rubin, Jordan, "The Impact of Pension Freezes on Firm Value," 2007. Working Paper.

Schrager, Allison, "A Life-Cycle Analysis of the Decline of Defined Benefit Plans and Job Tenure," 2006. Working Paper.

Zeldes, Stephen P., "Optimal Consumption with Stochastic Income: Deviations from Certainty Equivalence," The Quarterly Journal of Economics, 1989, 104 (2), 275-298. 
Table 1

Hard Frozen DB Plans

\begin{tabular}{lccc}
\hline \hline & 2003 & 2004 & 2005 \\
\hline Percent of Plans & 9.5 & 12.1 & 14.1 \\
Percent of Participants & 2.5 & 3.5 & 6.1 \\
Percent of Liabilities & 1.4 & 1.9 & 4.1 \\
\hline
\end{tabular}

Source: Pension Benefit Guaranty Corporation (2008) 
Table 2

Income process

\begin{tabular}{|c|c|c|}
\hline & High School & College \\
\hline \multicolumn{3}{|l|}{ Fitted age polynomials } \\
\hline $\begin{array}{l}\text { Constant } \\
\text { Age } \\
\text { Age }^{2} / 100 \\
\text { Age }^{3} / 10000 \\
\text { Replacement rate SS }\end{array}$ & $\begin{array}{c}-1.8497 \\
0.1410 \\
-0.2411 \\
0.1276 \\
0.4100\end{array}$ & $\begin{array}{c}-3.8790 \\
0.3517 \\
-0.6299 \\
0.3694 \\
0.3400\end{array}$ \\
\hline \multicolumn{3}{|l|}{$\underline{\text { Coefficient estimates }}$} \\
\hline Children in $\mathrm{HH}$ & $\begin{array}{c}0.0387 \\
(0.0029)\end{array}$ & $\begin{array}{c}0.0327 \\
(0.0049)\end{array}$ \\
\hline Adults in $\mathrm{HH}$ & $\begin{array}{c}0.2275 \\
(0.0043)\end{array}$ & $\begin{array}{c}0.1894 \\
(0.0072)\end{array}$ \\
\hline State UE Rate (pct) & $\begin{array}{l}-0.0164 \\
(0.0015)\end{array}$ & $\begin{array}{l}-0.0161 \\
(0.0022)\end{array}$ \\
\hline Constant & $\begin{array}{c}9.4755 \\
(0.0341)\end{array}$ & $\begin{array}{c}8.2021 \\
(0.6431)\end{array}$ \\
\hline $\mathrm{N}$ & 33551 & 16059 \\
\hline R-squared & 0.200 & 0.278 \\
\hline \multicolumn{3}{|l|}{ Variance decomposition } \\
\hline Permanent $\left(\sigma_{\zeta}^{2}\right)$ & $\begin{array}{c}0.0100 \\
(0.0005)\end{array}$ & $\begin{array}{c}0.0143 \\
(0.0007)\end{array}$ \\
\hline Transitory $\left(\sigma_{\epsilon}^{2}\right)$ & $\begin{array}{c}0.0733 \\
(0.0052)\end{array}$ & $\begin{array}{c}0.0750 \\
(0.0072)\end{array}$ \\
\hline
\end{tabular}

This table presents the fitted age polynomials, coefficient estimates, and variance decomposition from separate fixed-effects regressions for high school and college graduates of the natural logarithm of income on a full set of age dummies and the number of children living in the household. The data are taken from the 1980-2003 waves of the PSID. Income is a "post-government" concept that sums household labor income, public transfers, and private transfers and subtracts income and payroll taxes. We restrict the sample to respondents aged 20-65 with no additional adults apart from a spouse living in the household, and we exclude observations with incomes less than $\$ 3,000$ or greater than $\$ 3,000,000$. The estimation procedure for the error structure follows Carroll and Samwick (1997). 

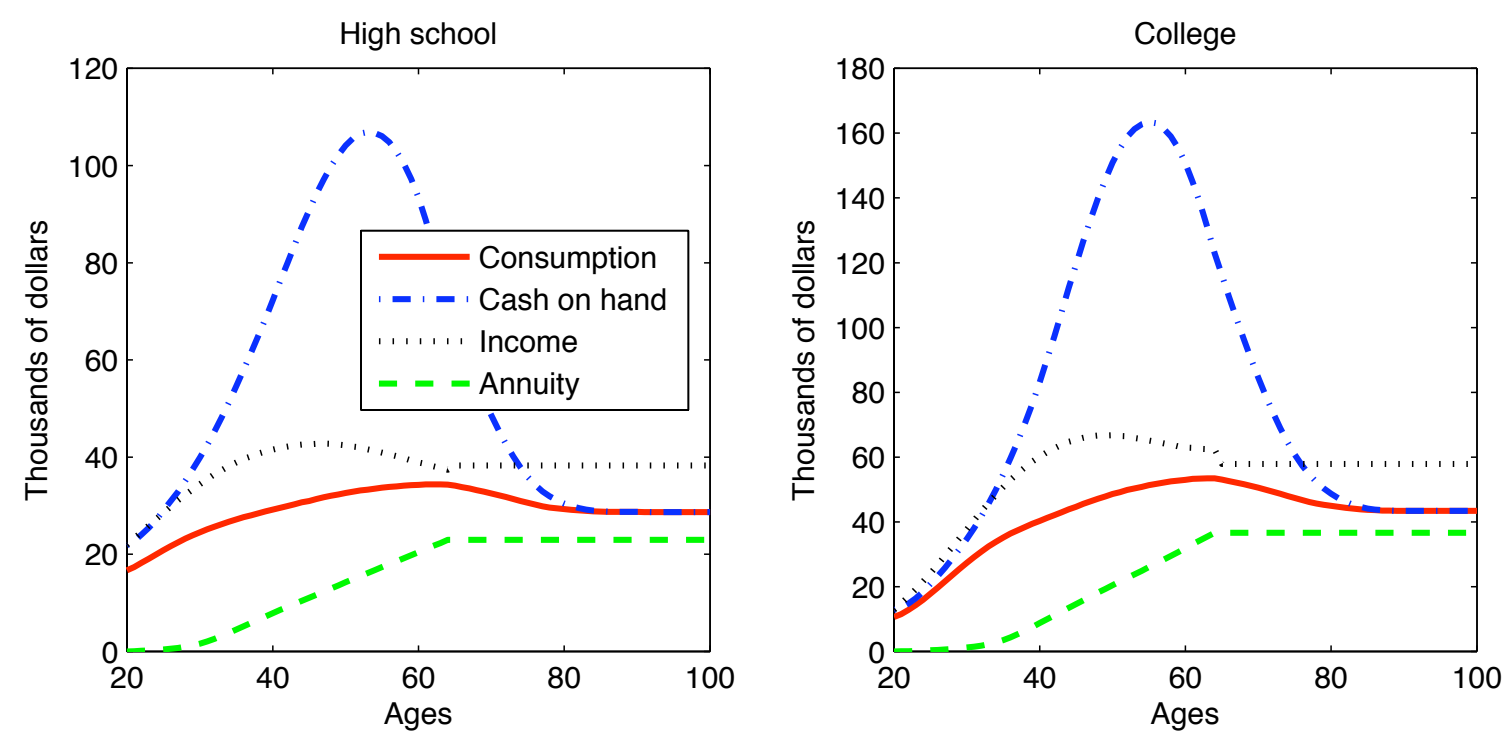

Figure 1

Simulated consumption, cash on hand, permanent income, and retirement annuity: The figure shows the average simulated levels of consumption $C_{t}$, cash on hand $X_{t}$, permanent income $P_{t}$, and the retirement annuity $A_{t}$ for high school graduates (left panel) and college graduates (right panel). The averages are taken over 20,000 independent life histories of income and employment shocks. The baseline model is solved for a coefficient of relative risk aversion of $\rho=3$, a bequest parameter $b=0$, a pre-tax interest rate of $r=5.5 \%$, a discount factor $\beta=1 /(1+r)$, a DB benefit generosity factor $\alpha=1.5 \%$, and a DC plan employer matching rate of $50 \%$ up to $6 \%$ of income. Note that in retirement, permanent income includes the value of the retirement annuity. 

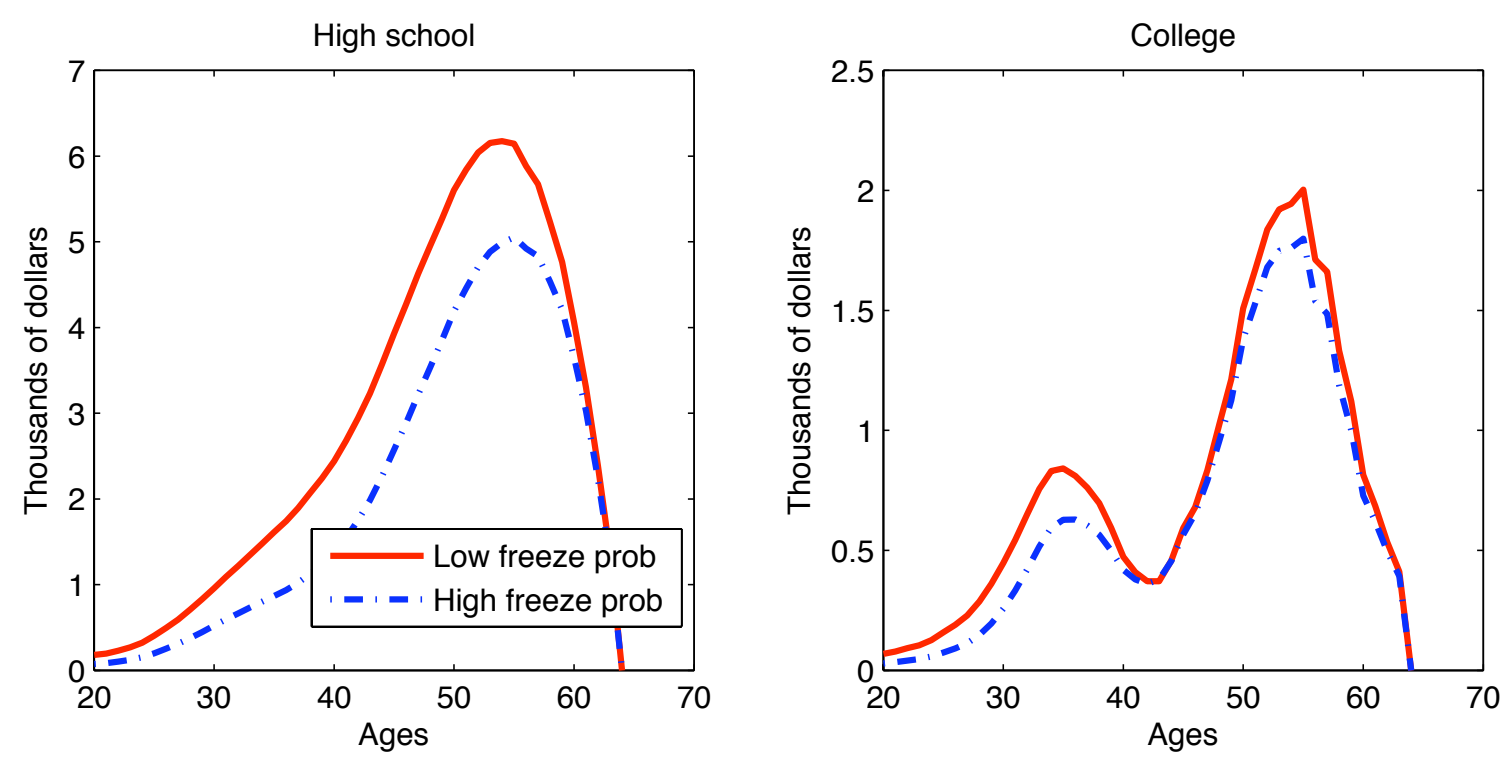

Figure 2

Simulated welfare costs of a pension freeze: The figure shows the average simulated welfare costs (the compensating equivalent values, in thousands) of experiencing a pension freeze at different ages during the working life. The left panel shows the welfare costs for high school graduates, and the right panel shows the welfare costs for college graduates. The "low freeze prob" lines represent the average welfare costs of pension freezes in an economy with a freeze probability of $1 \%$. The "high freeze prob" lines represent the average welfare costs of freezes in an economy with a freeze probability of $5 \%$. The averages are taken over individuals of each age, conditional on being employed by a firm offering a DB pension. The baseline model is solved for a coefficient of relative risk aversion of $\rho=3$, a bequest parameter $b=0$, a pre-tax interest rate of $r=5.5 \%$, a discount factor $\beta=1 /(1+r)$, a DB benefit generosity factor $\alpha=1.5 \%$, and a DC plan employer matching rate of $50 \%$ up to $6 \%$ of income. 

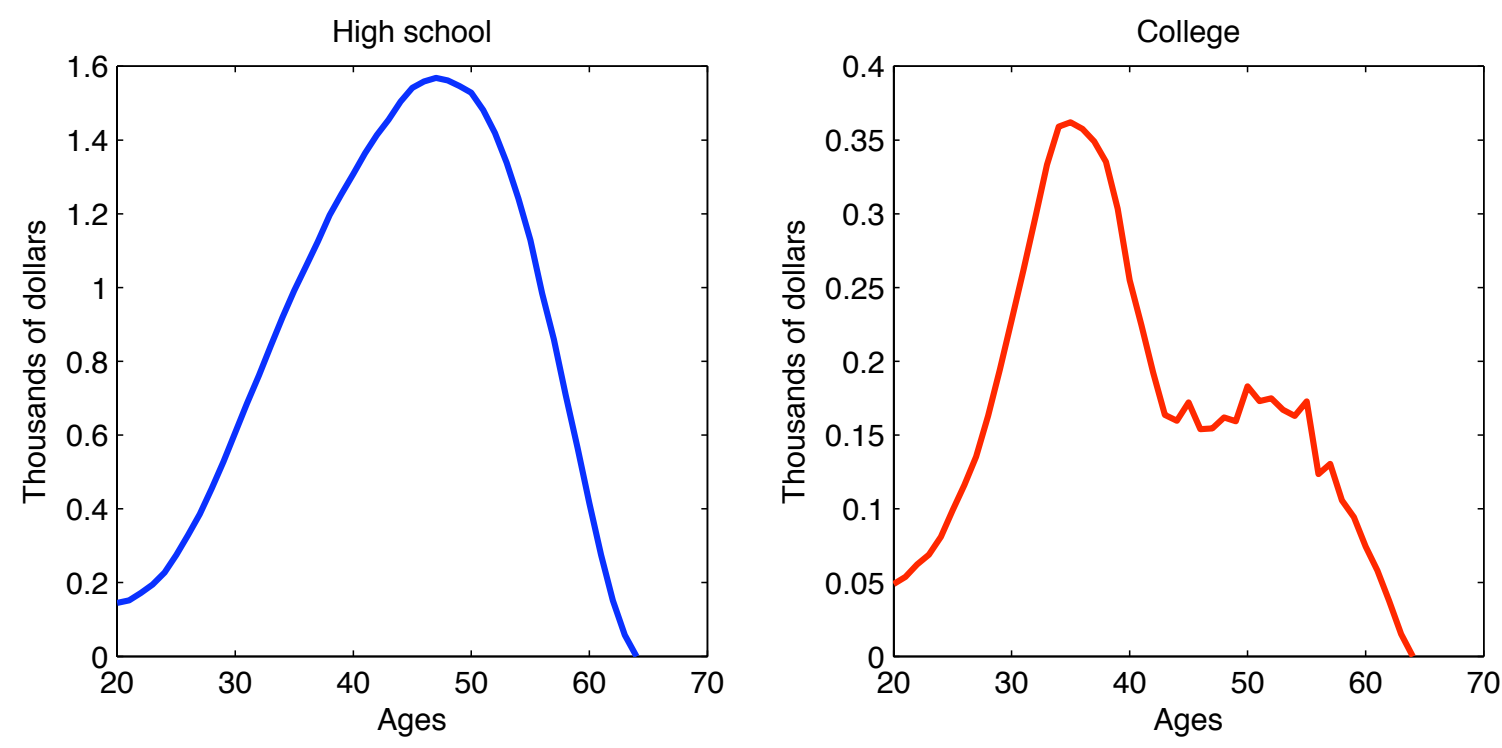

Figure 3

Simulated welfare costs of an increase in the probability of a pension freeze: The figure shows the average simulated welfare costs (the compensating equivalent values, in thousands) of a sudden increase in the probability of pension freezes (from a $1 \%$ risk to a $5 \%$ risk) for different ages during the working life. The left panel shows the welfare costs for high school graduates, and the right panel shows the welfare costs for college graduates. The averages are taken over individuals of each age, conditional on being employed by a firm offering a DB pension. The baseline model is solved for a coefficient of relative risk aversion of $\rho=3$, a bequest parameter $b=0$, a pre-tax interest rate of $r=5.5 \%$, a discount factor $\beta=1 /(1+r)$, a DB benefit generosity factor $\alpha=1.5 \%$, and a DC plan employer matching rate of $50 \%$ up to $6 \%$ of income. 

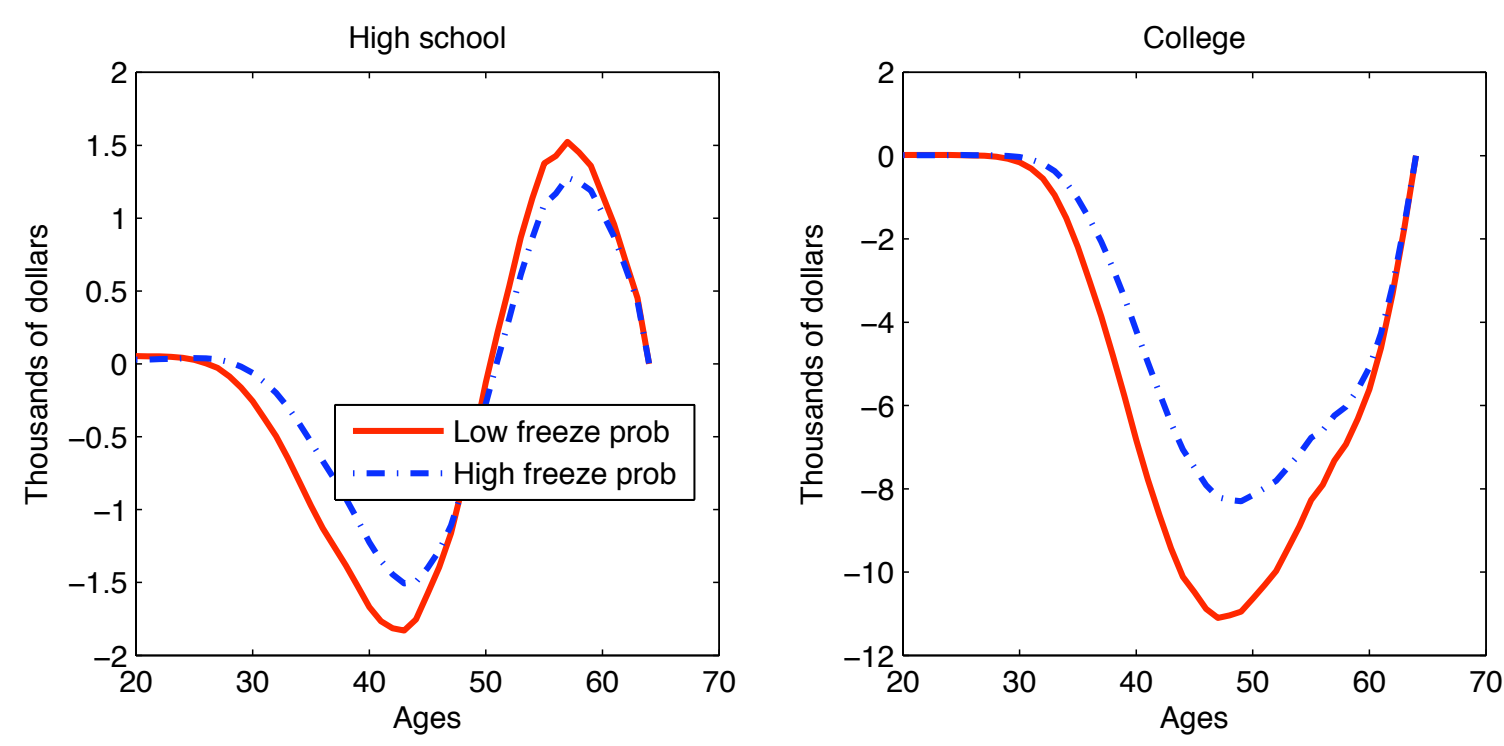

Figure 4

Simulated welfare costs of a pension freeze (with match set to equalize pension costs): The figure shows the average simulated welfare costs (the compensating equivalent values, in thousands) of experiencing a pension freeze at different ages during the working life. The left panel shows the welfare costs for high school graduates, and the right panel shows the welfare costs for college graduates. The "low freeze prob" lines represent the average welfare costs of pension freezes in an economy with a freeze probability of 1\%. The "high freeze prob" lines represent the average welfare costs of freezes in an economy with a freeze probability of $5 \%$. The averages are taken over individuals of each age, conditional on being employed by a firm offering a DB pension. The baseline model is solved for a coefficient of relative risk aversion of $\rho=3$, a bequest parameter $b=0$, a pre-tax interest rate of $r=5.5 \%$, a discount factor $\beta=1 /(1+r)$, a DB benefit generosity factor $\alpha=1.5 \%$, and a DC plan employer matching rate of $112 \%$ for high school graduates and $136 \%$ for college graduates up to $6 \%$ of income. 

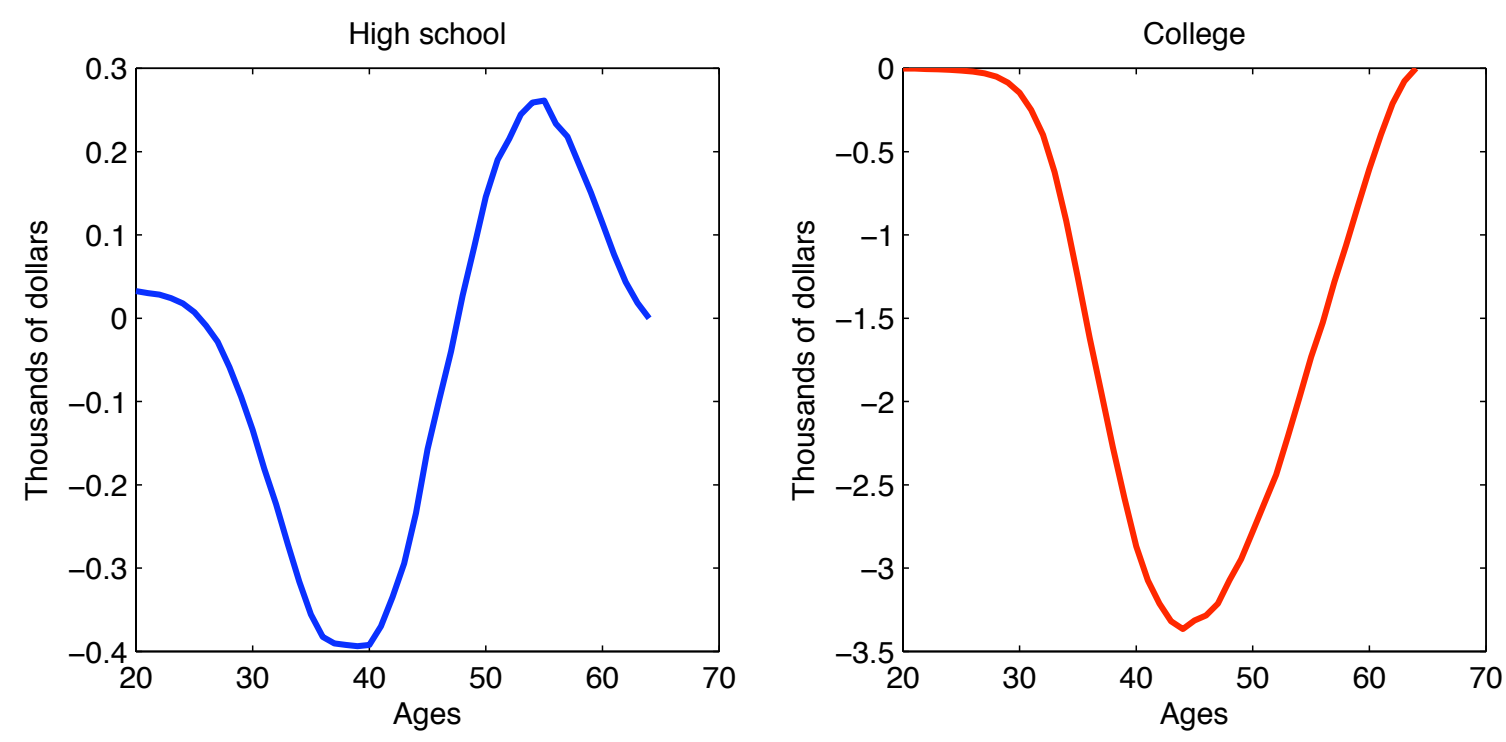

Figure 5

Simulated welfare costs of an increase in the probability of a pension freeze (with match set to equalize pension costs): The figure shows the average simulated welfare costs (the compensating equivalent values, in thousands) of a sudden increase in the probability of pension freezes (from a $1 \%$ risk to a $5 \%$ risk) for different ages during the working life. The left panel shows the welfare costs for high school graduates, and the right panel shows the welfare costs for college graduates. The averages are taken over individuals of each age, conditional on being employed by a firm offering a DB pension. The baseline model is solved for a coefficient of relative risk aversion of $\rho=3$, a bequest parameter $b=0$, a pre-tax interest rate of $r=5.5 \%$, a discount factor $\beta=1 /(1+r)$, a DB benefit generosity factor $\alpha=1.5 \%$, and a DC plan employer matching rate of $112 \%$ for high school graduates and $136 \%$ for college graduates up to $6 \%$ of income. 